\title{
The Exploration and Practice of Practice Ability Training for Mathematics Graduate Students in General Engineering University
}

\author{
Sheng-Kun Li
}

College of Applied Mathematics, Chengdu University of Information Technology, Chengdu, 610225, P.R. China

DOI: $10.36347 /$ sjahss.2020.v08i06.006

| Received: 04.06.2020 | Accepted: 15.06.2020 | Published: 30.06 .2020

*Corresponding author: Sheng-Kun Li

Abstract

Review Article

Taking the college of applied mathematics of a certain Western University as an example, this paper analyzes the enrollment, cultivation, employment and further education of the mathematics graduate students in general engineering university, and puts forward that the practical ability training of master candidate should be strengthened. By synthetic evaluating their multiple factors such as latent capacity in scientific research, personal willingness, family economical condition and support, distributary's cultivation has good effectiveness for master candidate's practical ability.

Keywords: Master candidate; mathematics; practical ability.

Copyright @ 2020: This is an open-access article distributed under the terms of the Creative Commons Attribution license which permits unrestricted use, distribution, and reproduction in any medium for non-commercial use (NonCommercial, or CC-BY-NC) provided the original author and source are credited.

\section{INTRODUCTION}

As we all know, mathematics is the foundation of all natural sciences, engineering technology, economic management and other disciplines. Today, all the economic, technological and military powers in the world are undoubtedly powerful in mathematics. Any famous university in the world must be supported by a strong mathematics discipline. There is no doubt that any master of science, engineering, economic management and other fields has a deep mathematical foundation. However, the education of mathematics postgraduates has not been paid enough attention, and the research of mathematics postgraduates' education in academia is less. As for the practical education of mathematics postgraduates, the paper [1-2] points out that even in a superpower such as the United States, the cultivation of mathematics postgraduates also attaches importance to scientific research ability and ignores the cultivation of teaching ability and application ability, so whether there is such a problem in China's mathematics postgraduates education is worthy of investigation and research, However, the existing research literature on the education of mathematics postgraduates mainly focuses on the construction of tutor team, curriculum setting, improvement of teaching means and cultivation of postgraduates' scientific research ability [3-8]. Therefore, it is of practical significance to explore the cultivation of the practical ability of mathematics postgraduates, especially for the education of mathematics postgraduates after enrollment expansion. For practical consideration, we consider general engineering colleges and universities and take the cultivation of mathematics graduate students in a general undergraduate college in the west China as an example to explore and practice the cultivation of practical ability of mathematics graduate students. The conclusion drawn from the investigation of a secondclass undergraduate college is not necessarily suitable for other second-class undergraduate colleges, more likely not suitable for key undergraduate colleges at all, but it can be used as a reference material for the study of other similar two engineering colleges and universities, as well as a comparative material for the study of key undergraduate colleges and universities.

The current situation and reasons of neglecting the cultivation of practical ability

At present, the training of practice ability of mathematics postgraduates is not enough, because there are many reasons.

In the aspect of training objective management, the graduate students of the considered university can graduate after meeting the requirements of four aspects: first, they are qualified in course learning and complete the required credits; second, they publish an academic paper in domestic and foreign academic journals; third, they write their graduation thesis and pass the evaluation and defense; fourth, they complete the teaching practice. The school has strict assessment methods for the first three requirements. Closed book examination is adopted in the assessment of professional degree courses in course learning; if the 
published thesis is a general public publication, the students must be the first author, and the journals above the core allow the tutor to be the first author or the second author; the graduation thesis requires the evaluation of experts outside the school, and some papers are randomly selected for blind examination according to a certain proportion, and the tutor is required to avoid when voting in reply. Graduate students and tutors attach great importance to the first three of the above four requirements, which not only determines whether graduate students can graduate to obtain master's degree, but also determines the evaluation of various awards for graduate students. At present, there are national scholarships with bonus of 20000RMB for postgraduates, and academic scholarships with bonus of 10000,8000 or 6000 RMB. The weight is heavy enough for most postgraduates. Academic scholarships are selected in the last period of each year. The academic scholarship grade is determined by the entrance examination results of the first year postgraduates. The second year postgraduates usually have no papers published in the third semester. The determination of academic scholarships is mainly based on research during the first period; the academic achievements are mainly determined by the level and quantity of published papers. It is particularly important for students to publish papers. Not only do they often decide whether they can get national scholarships and academic scholarships, but also the schools with SCI, EI, SSCI, CSSCI retrieval papers above the core have special excellent scientific research paper awards. In addition, the academic excellence awards, excellent class leaders, Three-Good students and provincial excellent academic dissertation awards at the school level are all based on the published scientific research papers evaluation index. In contrast, as one of the teaching practice process of practical ability, the university requires that the department should not take it as an indicator to evaluate various awards. The graduate department does not provide very specific implementation details and assessment methods. The teaching practice of mathematics graduate students in our college is to let the graduate students follow the public mathematics teachers such as linear algebra, higher mathematics and so on, whose curriculum tasks are more important under the influence of teaching practice training, but due to the number of class hours and other factors, the teachers of public mathematics only allow postgraduates to grade their homework. The academic affairs office and the teachers of class will not allow postgraduates to teach in person on the podium, and postgraduates rarely participate in the after-school questions answering of undergraduates.

In terms of tutors, the school implements the tutor responsibility system. In name, the tutor is required to be responsible for guiding and completing all training contents in the whole training process of postgraduates. In fact, the tutor is only responsible for guiding the academic research of postgraduates. As for whether the credits are completed or not, the students themselves are not responsible for the tutor. The teaching practice is arranged by the master in charge of the postgraduate class, and the teachers of the public mathematics department who are responsible for the guidance will pass the postgraduate examination in the teaching practice. Therefore, tutors tend to neglect the cultivation of practical ability of postgraduates.

\section{The necessity of strengthening the cultivation for practical ability}

The practical ability training of mathematics postgraduates is the practical need of the change of employment situation. Before the expansion of graduate enrollment, there was a shortage of graduate students. As long as they got master's degree, they could enter universities or scientific research institutes, which was in short supply. Therefore, at that time, only under the guidance of their tutors, they needed to follow their tutors' scientific research direction to complete their studies, and the tutors did not need to consider the practical ability of graduate students at all. Under the background of university education from elite education to popular education, and under the situation that the employment of students is dominated by the market demand, it is difficult for master's degree students to enter universities or scientific research institutes, especially for undergraduate universities, the demand for mathematics teachers generally requires doctor's degree. The employment of master of mathematics gradually takes middle school and enterprise as the main channel, so the practical application ability training of master of mathematics is particularly important.

It is particularly urgent to cultivate the practical application ability of the master of mathematics students in our university. The reasons are as follows: (1) from the perspective of students, we must consider the employment problem. If the employment channel is not smooth, it will affect the entrance of enrollment, so as to reduce the quantity and quality of students, and make the construction of master of mathematics fall into a bad cycle. Indirectly, it may also affect the promotion of other key disciplines in our university. Throughout the ages and at home and abroad, the universities of science and engineering with doctorates must have good mathematics as the backing. (2) At present, it is very difficult for the master of mathematics of our university to obtain the students with good foundation due to the competition of students in mathematics major of key universities and the students' personal preference for studying in "key universities" and "ordinary undergraduate colleges". From the historical data of enrollment, the master of mathematics of our university is generally the adjustment students who have failed to apply for the examination of key universities. (3) It's unrealistic for me to train my master's degree in mathematics to study in my university due to many factors such as my will 
and family economic conditions. (4) The requirements of university undergraduate employers for doctors, and even some vocational and technical universities and other colleges also put forward "doctor", "master of key universities", "master of short majors" and other employment restrictions. It will be more difficult for mathematics Postgraduates of our university to enter universities and scientific research institutes, and there will be pressure of employment competition from key universities. Take Chengdu as an example, our university has a master of mathematics in terms of employment; there are competitive pressures from key universities such as Sichuan University, Southwest Jiaotong University, University of Electronic Science and technology, Southwest University of Finance and economics and other universities. Entering middle school and enterprise will be the main future of our school's master of mathematics.

\section{Measures to strengthen the cultivation of practical ability}

After the expansion of postgraduate enrollment, the employment of master's degree student's in general undergraduate colleges and universities presents a more diversified situation, from the former main universities, scientific research institutes, and test programs to universities, scientific research institutes, test programs, middle schools, enterprises, etc., and gradually to middle schools, enterprises, and test programs. In order to adapt to the change of social situation, the practical ability education of Postgraduates needs to be strengthened and adjusted. The leaders and tutors in charge of postgraduate training in the school of applied mathematics of our university attach great importance to this, and carry out reform and exploration on the cultivation of master's degree in mathematics from many aspects. The practice of our university shows that these measures have good effect on postgraduate education or employment.

(1) When entering the school, we should explore the future development intention of the research freshmen as early as possible. In September of enrollment, a meeting between graduate students and tutor group will be held. The leaders of the Institute in charge of graduate training will introduce the research direction of each tutor and the postgraduates' examination and employment in previous years on behalf of the Institute. After the graduate students fully understand the situation, the graduate students will choose their tutors according to their research interests. After determining the tutor, the tutor will further understand the situation of the graduate student. From the perspective of students' study, it is an ideal path to continue to study for a doctor after finishing the master's degree, but in fact, it is unrealistic for every postgraduate to continue to study for a doctor. First of all, students should have the will to study for doctoral degree. Other people can't ask or hope that a certain student will become a doctor in the future. Second, students should have the knowledge base, the will to overcome difficulties and the research potential. It's difficult to complete doctoral study without keen insight into scientific research problems. Although conditions such as physical health, family support, family economic, etc, are not decisive factors but very important factors. The tutor needs to make a comprehensive analysis and evaluation from these various factors, and work together with the graduate students to develop a personal training program and training plan for the graduate students, so as to implement focused shunt training.

(2) As soon as possible, the students who are determined to apply for doctor's degree can realize the docking with domestic key universities and foreign universities, focusing on the cultivation of professional research ability. The development of the times has been very convenient for the resource sharing between key universities and general undergraduate universities. The overall Faculty of key universities is strong and the courses are complete. Graduate students of general undergraduate universities can attend lectures, lectures and materials in key universities, communicate with the doctoral directors of key universities as soon as possible, participate in their scientific research seminars and research topics, and complete the research plan required by the doctoral education as soon as possible. In addition, we should try our best to create conditions for graduate students to communicate with foreign universities. Even if graduate students cannot go abroad to exchange with foreign universities, we should also try our best to invite outstanding scholars from foreign universities to come in and provide short-term courses or academic lectures for graduate students, especially make full use of the rare resource of Chinese scholars working abroad.

(3) For those students who want to devote themselves to education immediately after graduation, they should focus on the cultivation of teaching practice ability, focusing on the problems in primary and secondary education as a scientific research topic, using mathematical tools for research and analysis. Establish diversified and targeted graduate teaching practice bases in our school, vocational and technical college and primary and secondary schools. Graduate students should engage in substantive teaching practice as early as possible under the guidance of the teachers in the practice base, so that they can formally take up their posts in the employing unit as soon as they graduate, and complete the training work of bringing the old with the new as soon as possible.

(4) For those students who want to enter the enterprise immediately after their master's degree, they should focus on training practical abilities such as mathematical modeling, data processing, algorithm realization, mathematical software, etc., build a platform for joint training of school and enterprise, take 
market demand as the guide, pay attention to discipline penetration, and cultivate innovative research talents with distinctive characteristics of applied mathematics. Encourage graduate students to actively participate in the National Graduate mathematical modeling competition, the American Mathematical modeling competition, the National Challenge Cup competition and other large-scale competitions, and actively carry out the social practice of using mathematical theoretical knowledge to solve practical problems.

(5) To provide system guarantee for strengthening the practice link. The practice link will be included in the evaluation system of graduate students' Graduation conditions and awards, and the graduation requirements will be revised. For example, one academic paper published in domestic and foreign academic journals previously is one of the necessary conditions for graduate students of our university to obtain graduation qualification, which can be revised to replace with other conditions that can represent the level of practice, such as in national and international large-scale mathematical modeling competition and selection The prizes won in the competition, such as the cup, are awarded at the county or district level or above in the teaching practice, and the invention patents in the production practice, etc. Let postgraduates and tutors not only pay attention to the cultivation of practical ability of postgraduates from the aspect of cognition but also from the aspect of action, break the monopolistic situation that only using academic papers to evaluate the excellence of mathematics postgraduates, and bring the cultivation of all-round excellent mathematics workers into one of the important goals of mathematics Postgraduates education.

\section{REFERENCE}

1. Gao Lingyun. Enlightenment of mathematics curriculum in American Graduate Education [J]. Higher science education. 2011, 4:66-68

2. Wang Bing. The trend and enlightenment of American mathematics graduate education reform [J]. Foreign education research. 1998, 1:36-40

3. Yang Anzhou, Ge Minghao. Two points of experience in training the professional ability of mathematics graduate students [J]. Degree and graduate education. 1986,4:16-18

4. Gong Zikun, Li Zhongru. Analysis and Enlightenment of postgraduate training mode of foreign mathematics education $[\mathrm{J}]$. Journal of Southwest Normal University (NATURAL SCIENCE EDITION). 2007, 32(1): 145-147

5. Wang Dingguo, Yuan Fang. Strengthening the construction of mathematics academic degree and training innovative mathematics talents $[\mathrm{J}]$. Journal of Qufu Normal University (NATURAL SCIENCE EDITION). 2010, 36(3): 116-119

6. Liu Runtao, Liu Xingfang. Discussion on the teaching mode of graduate students majoring in Applied Mathematics [J]. Education and teaching forum. 2011, 23: 109-110

7. Shi Zifu, Zhou Zhuozhao. A preliminary study on the ability and quality characteristics of graduate students in Mathematics Department of Normal University [J]. Psychological research. 2014, 7(4): 86-90

8. Wu Jinbiao, Liu Zaiming, Peng Yi. Teaching reform of postgraduates majoring in probability theory and mathematical statistics [J]. Mathematics theory and application. 2013, 33(1): 116-120. 